Revista de Ciencias Sociales - Número 70 (2017) - Páginas 27-58

Continuidad y discontinuidad: lógica hegeliana y estructura social straussiana

\title{
CONTINUIDAD Y DISCONTINUIDAD: LÓGICA HEGELIANA Y ESTRUCTURA SOCIAL STRAUSSIANA
}

CONTINUITY AND DISCONTINUITY: THE HEGELIAN LOGIC AND THE STRAUSSIAN SOCIAL STRUCTURE

\author{
LEODANIS TORRES BARRERO* \\ Universidad de Holguín, Cuba \\ ltorrest@.uho.edu.cu
}

\section{Resumen}

La relación entre lógica dialéctica, religión y matemática importa definirla, ante todo, porque es imprescindible para interpretar el surgimiento de los conceptos centrales del racionalismo moderno, metódico en su esencia, el cual formula principios que ha de normar la búsqueda de la verdad científico-natural y social. En este sentido la relación entre continuidad y discontinuidad es uno de los temas principales de la historia de la filosofía. Cuando Hegel y Lévi-Strauss analizan esas categorías en sentido filosófico y científico respectivamente no se limitan a su significado de la vida cotidiana.

\section{Palabras claves} tinuidad.

Lógica dialéctica, matemática, estructura social, continuidad, discon-

* Doctor en Ciencias Filosóficas por la Universidad Central Marta Abreu de las
Villas. Profesor principal de Historia del Pensamiento Político y de Lógica
Jurídica. Artículo recibido el 3 de abril de 2017 y aceptado el 29 de mayo de 2017.

Revista de Ciencias Sociales - Número 70 (2017) - Universidad de Valparaíso - ISSN 0716-7725-Valparaíso, Chile 


\begin{abstract}
The relation between dialectical logic, religion, and mathematics must first be defined, because it is essential to interpret the emergence of the central concepts of modern rationalism, methodical in its essence, which formulates principles that must regulate the search for scientific- Natural and social. In this sense the relation between continuity and discontinuity is one of the main themes of the history of philosophy. When Hegel and Levi-Strauss analyze these categories in a philosophical and scientific sense respectively, they are not limited to their meaning of everyday life.
\end{abstract}

\title{
Keywords
}

Dialectical logic, mathematics, social structure, continuity, discontinuity.

\section{Introducción}

Emprender un análisis del pensamiento filosófico de Hegel y del pensamiento científico de Lévi-Strauss, presupone una tarea compleja por el aparente aislamiento temporal y de contenido epistemológico entre ellos que despierta una primera mirada. Evitar las confusiones conceptuales y la falta de sistematicidad teórica es necesario para determinar sus ideas sobre el orden, lógica dialéctica, matemática, estructura social, continuidad, discontinuidad, etc., y la fundamentación de sus principios normativos. Se trata de desentrañar las categorías lógicas y científicas que están actuando en las esencias más profundas del problema de la verdad del conocimiento dialéctico que descubre la transición arraigada en el movimiento.

Precisamente el reconocimiento de la unidad entre continuidad y discontinuidad en la contradicción no es accesible de forma directa a los sentidos según se constata en Hegel y Lévi-Strauss, cuando hablan de las verdades matemáticas y su resolución en la práctica histórica. Solo examinando la naturaleza interna del objeto se comprende las formas externas en que se da lo interno. Hay textos referenciales de ambos autores que afianzan su método y facilitan la comprensión del debate científico y su repercusión social, en particular. Asumir el desafío de estos estudios implica el manejo de un conjunto de categorías que

Facultad de Derecho y Ciencias Sociales - Universidad de Valparaíso - Chile 
presentan una relativa vitalidad por las implicaciones prácticas e inmediatas que podrían tener en el decursar de la vida.

\section{Platón: concepto de ciencia, dialéctica y matemática}

En su Alcibíades o de la naturaleza del hombre, Platón distinguió entre lo que la inscripción "Conócete a ti mismo" del oráculo de Delfos "ordenaba al ojo que se mirase en una cosa, en la que el ojo pudiera verse" , por ejemplo, "en los espejos y en otros cuerpos semejantes", y aquella "[...] parte del alma, verdaderamente divina [...], donde es preciso mirarse, y contemplar allí todo lo divino [...], Dios y la sabiduría,

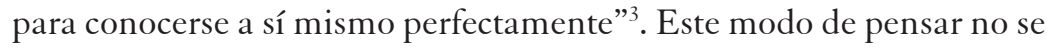
conforma con lo que el ojo describe, hay alguna parte del alma "en que residen la esencia y la sabiduría" 4 , la virtud, donde es necesario aplicar la reflexión si el espíritu desea ser reflejo de la virtud misma que perfecciona y aproxima al hombre a la esencia del Dios reflejado en él. El conocerse a sí mismo es el principio de todas las ciencias.

No tiene el mismo alcance referirse simplemente a los nombres de las ciencias que elaborar un concepto de ciencia, para ello resulta imprescindible el empleo de la razón. Esto desea Platón cuando en su Teetetes o de la ciencia, ese joven ante las preguntas de Sócrates sobre lo que es la ciencia, responde que con Teodoro "[...] se puede aprender $[\ldots]$ como la geometría y las otras artes [...], son otras tantas ciencias; y hasta todas las artes — continúa—, sea la del zapatero o la de cualquier otro oficio, no son otra cosa que ciencias" .

Pero Sócrates queda inconforme, nadie ignora que cuando "nombran el arte del zapatero" es porque "no quiere decir otra cosa que el arte de hacer zapatos" $\mathrm{y}$ "por el arte del carpintero [...], la ciencia

1. Platón: Alcibíades o de la naturaleza del hombre. Obras Completas, Buenos Aires: Anaconda, Ediciones Florida, 1946. Trad. de P. De Azcárate. Pág. 189.

2. Ídem.

3. Ibíd. Pág. 190.

4. Ídem.

5. Ibíd. Pág. 673.

6. Ídem.

Revista de Ciencias Sociales - Número 70 (2017) - Universidad de Valparáíso - ISSN 0716-7725-Valparáiso, Chile 
de hacer obras de madera". La razón de semejante pregunta "no es saber cuáles son los objetos de las ciencias" a Teeteto que solo pide "un objeto simple" y este ha respondido con "objetos muy diversos" en el sentido al "objeto a que se dirige cada una de estas ciencias"10; más bien "no nos proponemos contarlas — prosigue-, sino conocer lo que es la ciencia en sí misma" ${ }^{11}$. Ello es suficiente por cuanto la determinación del objeto de la ciencia está plagada de dificultades. Sócrates ambiciona explicar en qué consiste, aunque confiesa que no puede formarse por sí mismo una idea clara al respecto. El filósofo desea una explicación totalizadora y omnicomprensiva. Teeteto, discípulo aventajado del matemático Teodoro, llega a comprender que las ciencias particulares tienen objetos concretos y soluciones de procesos específicos:

La cosa me parece ahora fácil, Sócrates. La cuestión es de la misma naturaleza que la que nos ocurrió algunos días [...] Teodoro enseñaba algún cálculo sobre las raíces de los números, demostrándonos que las de tres y de cinco no son conmensurables en longitud con la de uno, y en seguida continuó así hasta la de diecisiete, en la que se detuvo. Juzgando pues, que las raíces eran infinitas en número, nos vino al pensamiento intentar el comprenderlos bajo un solo nombre, que conviniese a todos ${ }^{12}$.

Eso implica el empleo de cierto método de indagación científica y, a su vez, descubre particularidades y manifestaciones concretas de dicho fenómeno. No es casual que Sócrates pregunte: “¿Habéis ese descubrimiento?"13 Teeteto y otro discípulo tocayo de Sócrates descubren
7. Ídem.
8. Ídem.
9. Ídem.
10. Ídem.
11. Ídem.
12. Ibíd. Pág. 674.
13. Ídem. 
semejante axioma producto de la observación, la experimentación y la deducción lógica: "Dividimos todos los números en dos clases; los que pueden colocarse en filas iguales, de tal manera que el número de las filas sea igual al de unidades de que cada una consta, los hemos llamado cuadrados y equiláteros, asimilándolas a las superficies cuadradas"14. de bien:

Prosigue Teeteto luego de que Sócrates califica ese procedimiento

En cuanto a los números intermedios, tales como el tres, el cinco y los demás, que no pueden dividirse en filas iguales de números iguales, según acabamos de decir, y que se componen de un número de filas menos o mayor que el de las unidades de cada una de ellas, de donde resulta que la superficie que la representa está siempre comprendida entre lados iguales, a estos números los hemos llamado oblongos, asimilándolos a las superficies oblongas ${ }^{15}$.

Sócrates no podía menos que responder lo siguiente:

Perfectamente "¿Qué habéis hecho después de esto?”"16 Teeteto, acto seguido, explica que han "[...] comprendido, bajo el nombre de longitud, las líneas que cuadran el número plano y equilátero, y bajo el nombre de raíz a las que cuadran el número oblongo, que no son conmensurables por sí mismos en longitud con relación a las primeras, sino sólo por las superficies que producen. La misma operación hemos hecho respecto a los sólidos ${ }^{17}$.

Lejos de lograr una comprensión absoluta y universal de la ciencia, Teeteto reafirma que no se considera "con fuerzas para responder" como ha podido "hacerlo sobre la longitud y la raíz", pero sí llega a la conclusión de que la pregunta de Sócrates le "parece de la misma naturaleza"18. La cuestión no queda solucionada, sin embargo,
14. Ídem.
15. Ibíd. Pág. 675.
16. Ídem.
17. Ídem.
18. Ídem.

Revista de Ciencias Sociales - Número 70 (2017) - Universidad de Valparáíso - ISSN 0716-7725-Valparaíso, Chile 
Sócrates estimula a Teeteto a tomar "por ejemplo la preciosa respuesta de las raíces"19 e indica lo siguiente: "y así como las has abarcado todas bajo una idea general, trata de comprender en igual forma todas las ciencias en una sola definición" 20 .

La propuesta de este método es tentadora y desafiante, pues supone reflexionar sobre "el sentimiento de ciertas afecciones que pasan al alma por los órganos del cuerpo" ${ }^{21}$. Este proceso de construcción de la ciencia lleva a planteamientos de problemas, cuya solución abandona las apariencias y descubre la esencia: "La ciencia no reside en las sensaciones sino en el razonamiento sobre las sensaciones, puesto que, según parece, sólo por el razonamiento se puede descubrir la ciencia y la verdad, y es imposible conseguirlo por otro rumbo"22. Existe una formulación metodológica radical que propone anticipar lo fáctico como apariencia. Se plantea sustituir el relativismo sofístico, afirmando que todas las "afecciones, ver, oír, olfatear, resfriarse; calentarse"23, comprendidas "bajo el nombre genérico de sensación [...], no puede descubrir la verdad, porque no afecta a la esencia"24. El conocimiento seguro y confiable llega, entonces, por vía de las matemáticas, en cuanto ciencia formal capaz de hacer corresponder el pensamiento lógico con la realidad.

En consecuencia, para lograr identificar una estructura racional universal, "lo que importa - dice Platón en su Libro Séptimo de la República - es que el alma pase de la región de las tinieblas a la de la verdad; entonces se producirá la ascensión hacia el ser, a la que llamaremos la verdadera filosofía" ${ }^{25}$. Esta posición ontológica remite a las

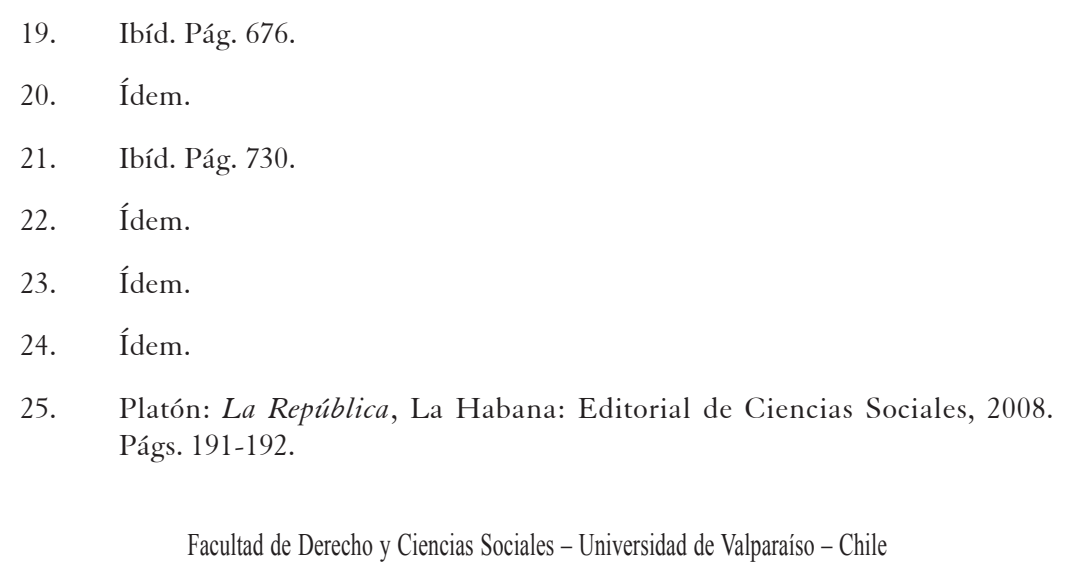


ciencias en tanto instrumentos de conocimiento del universo más allá de la realidad física sensible: “¿No convendrá investigar para ello el poder que pueden ejercer las distintas ciencias?; la ciencia del cálculo y la aritmética [...] Una y otra, pues, parece que conducen hacia la verdad [...] He aquí, según parece, que tenemos ya dos de las ciencias que buscamos" 26 . Una cosmovisión opuesta al sofismo que conviene, para el dominio de la política, la sensibilidad y la esencia.

La ciencia del cálculo y la aritmética "[...] son necesarias de todo punto al guerrero y al filósofo, al primero para la mejor ordenación de los ejércitos, y al segundo para que emerja del mundo perecedero hacia la esencia de las cosas, si es que se precia de hombre calculador [...] Y bien sabes tú que nuestro guardián habrá de ser guerrero y filósofo" ${ }^{27}$. Resulta más fácil refutar la libre utilización de la ciencia del cálculo por "los comerciantes y chamarileros" 28 , porque ni queda limitada "[...] tan sólo a las compras y a las ventas, sino que puede aplicarse a la guerra y a facilitar una vuelta del alma misma al mundo de la verdad y de la esencia [...]"29. La inversión platónica de los principios matemáticos de partida consiste en que ellos ahora conducen a "lo alto" y el alma queda obligada "a razonar sobre los números"30, contemplar su naturaleza. Esta fundamentación reivindica el método matemático no como el verdadero conocimiento, sino como una vía de la crítica misma a quienes presenten "el ejemplo de números corpóreos y tangibles" ${ }^{\prime 1}$.

El problema de unidad es para Platón una cuestión de suma importancia dentro de la reflexión sobre números, porque permitiría

\footnotetext{
26. Ibíd. Pág. 195.

27. Ídem.

28. Ibíd. Pág. 196.

29. Ídem.

30. Ídem.

31. Ídem.
}

Revista de Ciencias Sociales - Número 70 (2017) - Universidad de Valparáíso - ISSN 0716-7725-Valparaíso, Chile 
rebasar la apariencia tangible frente aquellos comerciantes y chamarileros, que trafican con la ciencia del cálculo y "no dan oídos al que trata de dividir la unidad en sî"32. Con esto muestra a sus contemporáneos que si él divide la unidad, “[...] ellos mismos la multiplican, temerosos de que la unidad no parezca lo que es, sino una reunión de partes $[\ldots]$ "..33. De aquí se sigue la dialéctica, que, por ser aquella en que con más seguridad los hombres de ciencia encaminan su inteligencia más allá de los límites de la experiencia, es necesaria a todas las ciudades estados. Por consiguiente, la dialéctica tiene el mismo fin y la misma necesidad atribuida a las ciencias, no ha sido una invención arbitraria.

En esta teoría están las ciencias, que acepta Platón para ascender al ser. La dialéctica parte del conocimiento científico, asimismo es crítica de las formas del pensamiento no dialéctico conforme con las apariencias, o que la verdad de una manera clara a los ojos de todos y no a la luz de la razón. El problema planteado está dirigido además, a los estudios de la armonía y la astronomía. Ambos adolecen del método correcto, por ejemplo, los dedicados a la ciencia del "movimiento armónico" quedan limitados, porque: "Buscan también los números en esos mismos acordes que escuchan, pero no se consagran a los problemas ni consideran, por tanto, qué números son armónicos y cuáles no, y por qué unos lo son y otros no" ${ }^{34}$. Con estas preguntas se inicia la dialéctica dado que están, en dicho caso, implícitas las cuestiones de unidad, identidad y diversidad. Platón plantea dicha cuestión por el argumento previo de que "de los sentidos nada sano puede esperarse" 35 .

Ahora bien, vale perfectamente esta consecuencia: "[...] la dialéctica $[\ldots]$ es una arte que, a pesar de su raíz inteligible, puede ser imitada por la facultad de la vista, a la que atribuimos el intento de dirigirse hacia los animales, a los astros y, en definitiva, al mismo sol [...]"36. Platón sostiene aquí que el camino de las sensaciones es limitado

\footnotetext{
32. Ídem.

33. Ídem.

34. Ibíd. Pág. 202.

35. Ibíd. Pág. 193.

36. Ibíd. Págs. 202-203.
}

Facultad de Derecho y Ciencias Sociales - Universidad de Valparaíso - Chile 
por ser aplicable solo a los objetos fáciles de observar y cuantificar y, sin embargo, así entendido pueden acercarse a ellos con aptitud dialéctica en tanto sean reflejados como una multiplicidad, entonces habrá cierta correspondencia entre los objetos y su reflejo a través de los sentidos. "Y así, cuando alguien utiliza la dialéctica y prescinde en absoluto de los sentidos, pero no de la razón, para elevarse a la esencia de las cosas, y no ceja en su empeño hasta alcanzar por medio de la inteligencia lo que constituye el bien en sí, llega realmente al término mismo de lo inteligible, como llegó también el dialéctico antedicho al término mismo de lo visible" ${ }^{37}$. Pero esta reflexión platónica sobre las sensaciones ya es dialéctica, pues señala el método para resolver lo inadecuado de aquel reflejo; luego es también una teoría sobre la realidad que se piensa.

A partir de esa correlación de las ciencias y la dialéctica se establece el método considerado como medio único capaz del reflejo del ser, otra realidad diferente a la vivida, o la verdadera realidad problematizada de forma rigurosa; debe buscarse la verdad detrás de las apariencias. Si se está, le dice Platón a su interlocutor Glaucón “[...] en lo cierto o no, es cosa que no vale la pena discutir. De lo que no podemos dudar es de la conveniencia de ver algo semejante $[. .$.$] "38. Más adelante señala "que$ solo la facultad dialéctica puede realmente mostrarlo a quien se halle práctico en las ciencias de que hemos hablado"39. Esta búsqueda supone cierta aptitud crítica de reafirmación del cambio valorativo sobre lo político por parte del filósofo.

\subsection{Crítica dialéctica, ciencia del cálculo y determinación universal}

Tales afirmaciones indican que si bien el racionalismo platónico busca más allá de la objetividad del mundo sensible la determinación universal, no es menos cierto que su posición lógico-ontológica proporciona un sentido a los saberes de todo cuanto existe: “[...] se nos

\footnotetext{
37. Ibíd. Pág. 203.

38. Ídem.

39. Ídem.
}

Revista de Ciencias Sociales - Número 70 (2017) - Universidad de Valparáíso - ISSN 0716-7725-Valparáiso, Chile 
ofrece ya algo que nadie podrá discutir, y es que únicamente por este método podrá llegar a descubrirse la esencia de cada cosa. Porque casi todas las demás artes se ocupan o de las opiniones de los hombres o de sus deseos, o de la generación y de las producciones, o del cuidado absorbente de las cosas nacidas o fabricadas" ${ }^{\prime 0}$. Lo conocido aquí es según criterios y prácticas mecánicas, o artesanales ajenas a la dialéctica, la cual de hecho los presupone para atribuirles sentidos diferentes al proceso de la cognición del bien en sí. Ni siquiera esas artes podrían aprehender, en cada caso, el conocimiento parcial del ser.

La formación de conceptos universales es la comprobación del orden jerárquico cimero que ocupa la dialéctica. La verdad del ser puede alcanzarse si previamente se reflexiona sobre las cosas variables que conducen a la generación y muerte, a fin de excluir las artes mecánicas y la doxa en la construcción del sentido. Estas no pueden trazarse el fin de aprehender el ser, dado que este no es objeto de sensación alguna. El filósofo tiene la capacidad de alcanzar ese fin no partiendo, sin embargo, de las cosas singulares ni de su reflejo; pero Platón se ve en la necesidad de someter a crítica toda utilización vulgar tanto de las matemáticas como los estudios relacionados con la armonía musical y la astronomía.

De ahí, que Platón cree asimilar esa crítica de manera corriente, en la medida en que fuese útil para alejar el pensamiento dialéctico del uso superficial mercantil de la ciencia del cálculo. Un espíritu no limitado a "números corpóreos y tangibles" sería educado y ejercitado, porque esa ciencia se le presentaría "con visos de necesaria, puesto que parece forzar al alma a servirse de la inteligencia pura para alcanzar la verdad en sî” ${ }^{41}$. Esto es insistir en un modo de pensar diametralmente opuesto a la vía que limita a las cosas singulares del mundo sensible. El alma intelectiva ha olvidado el mundo de las ideas donde antes residía.

El conocimiento de la esencia del ser, entonces, es innato apriorístico, para recuperarlo hace falta apropiarse de la dialéctica. Platón intenta separar las ideas innatas de las imagines sensibles, a pesar de que el tráfico vulgar de la ciencia del cálculo ha despertado su interés

40. Ibíd. Pág. 204.

41. Ibíd. Pág. 196.

Facultad de Derecho y Ciencias Sociales - Universidad de Valparaíso - Chile 
de la ascensión dialéctica. Depurar las ciencias necesarias para alcanzar la verdad en sí excluye el reflejo sensorial del mundo exterior como un momento del saber verdadero.

\subsection{Hegel: religión, demostración matemática y unidad entre identidad y diferencia}

La filosofía moderna, cuyo nacimiento se atribuye a Renato Descartes, conserva en su teoría del conocimiento a Dios, causa de la uniformidad e identidad del alma y el cuerpo. El materialismo francés del siglo XVIII, ejemplo, Holbach y Condillac, que tiene al empirista inglés John Locke como uno de sus referentes, además proclamar la libertad de la razón ante toda autoridad religiosa, busca el conocimiento fuera de la fe; aunque es un sistema pobre en comparación con Spinoza y Leibniz. El método filosófico, sin embargo, es análogo al de las matemáticas (mathesis universalis) en cuanto a res extensa, realidad natural, corpórea y cuantitativa. Pero es en Hegel donde se definen los contornos entre filosofía, matemática y religión de forma consciente, a partir de lo que considera como "contraposición entre el ser y el pensar" respecto: "La misión de la novísima filosofía alemana consiste en tomar ahora como objeto y en comprender la unidad del pensamiento y el ser, que es la idea central de toda filosofía: es decir, en captar lo más recóndito de la necesidad, el concepto" ${ }^{\text {*3. }}$.

El camino gnoseológico desde Descartes comenzaba a vislumbrar su punto final. Los dos polos latentes en la acepción más amplia de la teoría del conocimiento llega al límite de la contradicción y Hegel cobra conciencia de ello, es preciso resolver la unidad entre el sujeto y el objeto, problema que ya Spinoza observaba, en todo caso extensión y pensamiento como atributos de la naturaleza:

Una idea verdadera debe de estar de acuerdo con el objeto cuya idea es $[\ldots]$, es decir [...], lo que está contenido objetivamente en el

\footnotetext{
42. HEGEL, Federico Guillermo: Lecciones sobre historia de la filosofía, México: Fondo de Cultura Económica, Tomo I, 1955. Págs. 102-103.

43. Ibíd. Pág. 407.
}

Revista de Ciencias Sociales - Número 70 (2017) - Universidad de Valparáíso - ISSN 0716-7725-Valparaíso, Chile 
entendimiento debe existir necesariamente en la naturaleza; solo existe en Naturaleza una sustancia, a saber: Dios [...]; por consiguiente, un entendimiento, actualmente finito o actualmente infinito, debe comprender los atributos de Dios y las afecciones de Dios, y ninguna otra $\operatorname{cosa}^{44}$.

Spinoza sigue un pensamiento especulativo para construir los conceptos y, esto agrada a Hegel, pero aún no se plantea y delimita, con entera nitidez, las diferencias entre la forma del conocimiento del objeto en la filosofía y las formas del conocimiento del objeto en la religión y las matemáticas. Es indispensable, si se quiere adquirir plena conciencia de la contradicción, el planteo y solución de este problema, ello permite esclarecer los respectivos campos de conocimiento: "Lo que la filosofía tiene de común [...], principalmente, con la religión son los problemas absolutamente generales que constituyen su contenido; son las modalidades en que la suprema idea existe para la ciencia no filosófica, para la conciencia sensible, intuitiva, imaginativa [...]"45.

La lógica de su superación implica en todo caso, que la filosofía a diferencia de la religión se transforma, o se acerca, a la forma de la ciencia, es decir, conoce y aprehende la ley del objeto; pero por una vía diferente de las ciencias positivas, a través de las determinaciones construidas por el pensamiento sobre los objetos externos. No obstante, Hegel le atribuye a la "conciencia imaginativa" entendida dentro de la experiencia usual, el encargo "[...] de decirnos que hay, por lo menos, multitud de cosas contradictorias, de ordenamientos contradictorios, cuya contradicción no reside simplemente en una reflexión externa, sino en ellos mismos [...]" ${ }^{46}$. En el sentido hegeliano, la función de la filosofía le viene impuesta por su objeto, "es la ciencia objetiva de la verdad, la ciencia de su necesidad, de su conocer reducido a conceptos y no un simple opinar o devanar de opiniones" ${ }^{\prime 7}$.

44. SPINOZA, Baruch: Ética, La Habana: Editorial de Ciencias Sociales, 2006. Pág. 34.

45. HEGEL, Federico Guillermo: ob. cit. Pág. 62.

46. HEGEL, Federico Guillermo: Ciencia de la lógica, Buenos Aires: Editorial Hachette, 1956. Trad. de R. Mondolfo. Págs. 67-70.

47. HEGEL, Federico Guillermo: Lecciones sobre historia de la filosofía, ob. cit. Pág. 18.

Facultad de Derecho y Ciencias Sociales - Universidad de Valparaíso - Chile 
La religión tiene que ver con representaciones, intuiciones, fantasías; lo que se representa de una cosa de la vida natural, "la expresión de que Dios ha engendrado un hijo" ${ }^{\text {" }}$. La verdad, por su parte, es reflejo del movimiento del concepto y solo así comprueba el orden de los hechos. "La imaginación tiene siempre, sin duda, como contenido la contradicción pero no llega a cobrar conciencia de ella" ${ }^{4}$, en cambio, las estructuras del concepto explican las contradicciones. "La filosofía piensa y llega, así, a comprender lo que la religión se representa como objeto de la conciencia, ya sea como obra de la fantasía, ya como existencia histórica" ${ }^{50}$. La "imaginación [...] queda como reflexión externa, que pasa de la igualdad a la desigualdad, o de la relación negativa al ser reflejado de los diferentes en sí. Encierra estas dos determinaciones externamente puestas entre sí y tiene presentes sólo aquellas, pero no su transición, que es lo esencial y que contiene la contradicción" ${ }^{\prime \prime}$.

La verdad del conocimiento dialéctico, de tal forma, comprueba que la conciencia religiosa no capta la transición enraizada en el movimiento. Es precisamente el reconocimiento de la unidad entre identidad y diferencia la característica de la lógica interna del desarrollo. El concepto es el pensamiento de la contradicción no accesible de forma lineal a los sentidos. Solo examinando la naturaleza interna del objeto se comprende las formas externas en que se da lo interno. Esta reparación gnoseológica es necesaria, según Hegel, cuando se habla de las verdades matemáticas, porque "[...] aun menos podríamos considerar como geómetra a quien, sabiendo de memoria el teorema de Euclides, lo supiese sin sus demostraciones, no lo supiese en su interior [...] Y del mismo modo habría que considerar no satisfactorio el conocimiento que alguien, midiendo muchos triángulos rectángulos, pudiera adquirir

\section{Ibíd. Pág. 75.}

49. HEGEL, Federico Guillermo: Ciencia de la lógica, ob. cit. Pág. 134.

50. HEGEL, Federico Guillermo: Lecciones sobre historia de la filosofía, ob. cit. Pág. 75.

51. HEGEL, Federico Guillermo: Ciencia de la lógica, ob. cit. Pág. 135. 
acerca del hecho de que sus lados presentan la conocida proporción $[\ldots]^{\prime \prime 5}$.

La elucidación de esta dificultad específica en el conocimiento matemático tiene gran significación para la comprensión de las limitaciones gnoseológicas con que puede tropezar un estudiante o aficionado a dicha ciencia. El razonamiento que fundamenta la veracidad por medio de proposiciones es posible porque la actividad cognoscitiva aglomera e interpreta datos y obtiene teorías estructuradas con nuevos conceptos, al menos pensar el recorrido histórico de semejante conocimiento constituye una evasión plausible contra el aprendizaje mecanicista.

Sin embargo, Hegel considera que "el movimiento de la demostración matemática no forma parte de lo que es el objeto, sino que es una operación exterior a la cosa" ${ }^{53}$, pues "solo representa el devenir del ser allí" ${ }^{54}$ y no el "devenir de la esencia o de la naturaleza interna de la cosa" ${ }^{55}$. El ideal del carácter científico debe darlo la nueva filosofía alemana que unifica "lo uno y lo otro" ${ }^{" 56}$ no ya las matemáticas limitadas al conocimiento de leyes cuantitativas "y del que se jacta también en contra de la filosofía" 57 . Para tener mayor claridad sobre esta lógica del entendimiento es conveniente precisar que Hegel advierte la presencia de una "relación inesencial aconceptual" 58 en el concepto magnitud. "[...] Aquí, el movimiento del saber opera en la superficie [...] La

52. HEGEL, Federico Guillermo: Fenomenología del espíritu. En: Dominic Oliva, Eduardo (comp): Antología. Historia de la Filosofía. Filosofía Clásica Alemana, La Habana: Editorial Félix, Tomo V, 2013. Pág 170.

53. Ibíd. Pág. 171.

54. Ídem.

55. Ídem.

56. Ídem.

57. Ídem.

58. Ibíd. Pág. 172.

Facultad de Derecho y Ciencias Sociales - Universidad de Valparaíso - Chile 
materia acerca de la cual ofrece la matemática un tesoro grato de verdades es el espacio [...] un elemento vacío y muerto [...]" ${ }^{\prime 59}$, donde las diferencias del concepto "[...] son, por tanto, igualmente inmóviles e inertes. Lo real no es algo espacial, a la manera como lo considera la matemática; ni la intuición sensible concreta ni la filosofía se ocupan de esa irrealidad propia de las cosas matemáticas [...]" ${ }^{60}$.

Hegel pretende que esos conceptos cobren vida y movimiento hasta llegar a la identidad de los contrarios, por ejemplo, la unidad de lo finito y lo infinito no debe ser resultado arbitrario de una conciencia limitada a lo exterior: "El infinito progreso expresa algo más que la simple comparación de lo finito con lo infinito; implica también la conexión de elementos que son diferentes" ${ }^{\prime 1}$. Por ello, este infinito matemático fue contrario de los prejuicios y métodos del momento:

Pero, en el método del infinito matemático, la matemática encuentra una contradicción radical al mismo método que le es característico y en el que se basa como ciencia. Porque el cálculo del infinito admite, y exige, métodos de procedimientos que las matemáticas, cuando operan con magnitudes finitas, tienen que rechazar de plano, y al mismo tiempo trata estas magnitudes infinitas como quanta [cantidades] finitas, intentando aplicar a los primeros los mismos métodos que son válidos para estas últimas ${ }^{62}$.

\subsection{Dialectización de la matemática: unidad entre continuidad y discreción}

$\mathrm{Al}$ mismo tiempo que existe negación del cambio de método en la matemática por parte del sujeto, esta ciencia se va dialectizando. En estos casos, la definición del infinito tiende hacerse más allá de cualquier posición contrapuesta a la veracidad del cálculo referido, porque el

\footnotetext{
59. Ídem.

60. Ídem.

61. HEGEL, Federico Guillermo: Ciencia de la lógica, ob. cit. Pág. 160.

62. Ibíd. Pág. 226.
}

Revista de Ciencias Sociales - Número 70 (2017) - Universidad de Valparáíso - ISSN 0716-7725-Valparáiso, Chile 
infinito es real, y, si es real, cuenta con un contrario natural. Se deduce, entonces, " $[\ldots]$ que ninguna de estas dos determinaciones [continuidad y discreción], tomada por sí sola, tiene verdad, sino que la tiene sólo su unidad. Tal es la consideración verdaderamente dialéctica de ellas, y tal también su verdadero resultado" ${ }^{63}$.

La dialectización de la matemática que tiene su punto moderno de partida en la magnitud variable del propio Descartes y complementado por el desarrollo del cálculo diferencial e integral en los casos de Newton y Leibniz, significó mucho para Hegel, porque reafirmó su ideal del conocimiento científico. Este ideal llama la atención sobre el método axiomático-deductivo no para quedarse en él sino en el sentido del papel de la cantidad, cuya "completa determinación es el número" ${ }^{4}$ y luego enfatiza que: "Cuanto más ricos en determinaciones - y por lo tanto en relaciones - son los pensamientos, más intrincada, por una parte, y por otra más arbitraria y carente de sentido se torna su representación en formas tales como los números" ${ }^{65}$.

El método dialéctico hegeliano y el ideal científico que le acompaña es portador, en sentido general, del concepto platónico de filósofo calificado como alguien "[...] que no es a una parte de la cosa a la que ama y a la otra no, sino a la cosa en su totalidad [...]. Por consiguiente [...], diremos también del filósofo que ama la sabiduría, no en parte, sino en su totalidad" ${ }^{\prime 6}$. Siguiendo a este filósofo, el uso de la razón sería una búsqueda de la identidad del ser y lo diverso, o lo que es lo mismo según Aristóteles: la filosofía "no se identifica con ninguna de las que hablan parcialmente del ser, porque ninguna de las demás ciencias se ocupa del ser como ser, con su universalidad" ${ }^{67}$, lo cual sería una reflexión que integrase los conceptos apuntados en el orden de la totalidad.

63. Ídem.

64. Ibíd. Pág. 234.

65. Ibíd. Págs. 248-249.

66. Platón: La República, ob. cit. Págs. 149-150.

67. Aristóteles: Metafísica. Política, La Habana: Editorial Estudios, 1968. Pág. 95.

Facultad de Derecho y Ciencias Sociales - Universidad de Valparaíso - Chile 
De lo que se trata en Hegel es de una reflexión filosófica que pretende constituirse al fin en una filosofía como ciencia, según la concepción griega de metafísica, entendida como filosofía primera. Sin embargo, es impropio llamarle a la reflexión lógico-ontológica platónica y aristotélica, por ejemplo, filosofía del derecho; porque el nomos (sea costumbre o ley) tiene un discurso sobre el derecho, el cual es reflexionado esencialmente, integrado al ethos, la moral; logos, el concepto; y polis, la idea de organización del Estado. No puede haber en este filosofar dialéctico griego, en torno a la identidad del ser con la totalidad, una historia autónoma de filosofías ya sea jurídica, natural, etc. El derecho, siguiendo este ejemplo, está integrado a la moral, porque se orienta a la conducta humana y está, a su vez, integrado a la política debido a que se ocupa de la organización de la polis en función del bien $^{68}$; por cuanto para Aristóteles el hombre es un animal político por naturaleza dado que vive en colectividad. Es en su obra Política donde fundamentalmente la reflexión filosófica sobre el derecho se complementa como un todo orgánico.

En consecuencia, Aristóteles en su Ética Nicomaquea afirma que: "De lo justo político una parte es natural, otra legal [...], el justo será observante de la ley y la igualdad; lo injusto lo ilegal y lo desigual. Todas las cosas legales son de algún modo justas [...]. Justo, es también, lo que produce y protege la felicidad y sus elementos en la comunidad política [...]. La justicia así entendida es la virtud perfecta, pero no absolutamente, sino en relación a otra" ${ }^{” 9}$.

La filosofía primera ubica el derecho (lo particular) en relación con el orden de la totalidad (lo universal) y reconoce la totalidad en el derecho. El deber ser del derecho indica la corrección natural de lo justo político. "Natural — dice Aristóteles — es lo que en todas partes tiene la misma fuerza y no depende de nuestra aprobación o desaprobación"70. He aquí una particularidad de su reflexión filosófica sobre el derecho.

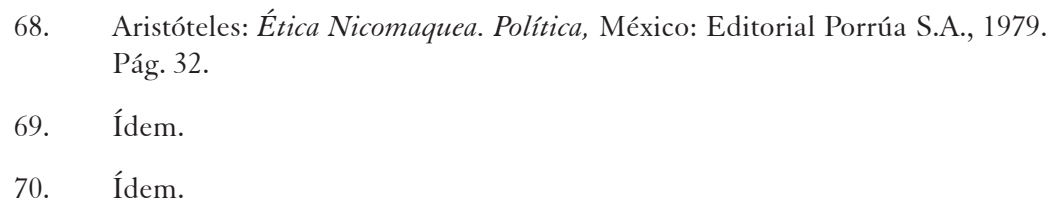

Revista de Ciencias Sociales - Número 70 (2017) - Universidad de Valparáíso - ISSN 0716-7725-Valparaíso, Chile 
La transformación de la metafísica realizada por Kant, en la filosofía moderna, requería según él mismo de una crítica que argumentara la búsqueda del absoluto o de la totalidad y encarrilara la propia metafísica en la marcha segura de una ciencia, para el uso de la posteridad como una construcción completa ${ }^{71}$. No cabe aquí tampoco la pretendida "Filosofía del Derecho" como un saber autónomo.

En su Introducción a la Teoría del Derecho, Kant afirma que: "El derecho como doctrina sistemática se divide en derecho natural, que descansa en principios a priori y derecho positivo o estatutario, que procede de la voluntad del legislador" ${ }^{2}$. No le tituló a esa obra "Filosofía del Derecho", justamente la teoría del derecho fue pensada a partir de la totalidad. El llamado kantiano sería incorporar la reflexión científica sobre el derecho a la conciencia crítico-trascendental.

Kant asevera que la ciencia del derecho es el conocimiento sistemático del derecho natural ${ }^{73}$, lo expone como idea racional a priori, determinada no por el contenido empírico de la libertad, sino sólo por el de su forma. Precisamente, la tarea crítica de exponer y deducir el derecho natural independientemente de motivaciones empíricas, es lo que determina la objetividad que intentó darle al concepto de derecho (basado en la libertad de arbitrio), al postular un conjunto de principios racionales que, aun no partiendo de la experiencia jurídica, explicaran, sin embargo, su posibilidad.

Eso es lo que procura realizar bajo la idea de los Principios metafísicos de la doctrina del derecho, a partir del cual se define el concepto de derecho natural con base a principios a priori constitutivos de la libertad: "El derecho es el conjunto de condiciones bajo las cuales el arbitrio de uno puede conciliarse con el arbitrio del otro según una ley universal de la libertad" 74 .

71. KANT, Emmanuel: “Crítica de la razón pura”. En: Eduardo Dominic Oliva: Antología. Historia de la Filosofía. Tomo V. Filosofía Clásica Alemana, Editorial Félix Varela, La Habana, 2013. Págs. 44-45.

72. KANT, Emmanuel: Introducción a la Teoría del Derecho, Madrid: Instituto de Estudios Políticos, 1964. Pág. 97.

73. KANT, Emmanuel: Metafísica de las Costumbres, Madrid: Tecnos, 1989. Trad. y notas de Adela Cortina Orts y Jesús Conill Sancho. Pág. 8.

74. Ibíd. Pág. 39.

Facultad de Derecho y Ciencias Sociales - Universidad de Valparaíso - Chile 
Hegel cuando arremete contra la lógica antigua y la Ilustración, de la que formó parte también Kant, sostiene que la filosofía es el conocimiento de la totalidad. "La ciencia filosófica del derecho tiene por objeto la idea del derecho, el concepto del derecho y su realización"75, pero el saber dialéctico implica aprehender el concepto del derecho que es el sujeto en la filosofía hegeliana, su máxima realización es el Estado ético, la eticidad superadora de todas las etapas anteriores.

El derecho está dentro del proceso de la superación. Ello se debe a que Hegel trata el poder y el Estado como el centro de su sistema filosófico en materia política. Realmente lo que hay es una reflexión filosófica sobre el derecho explícita en su filosofía política que rompe con la tradición iusnaturalista, pero insiste en crear sistemas. Hegel cuando plantea su concepto de derecho lo hace considerando al Estado como el reino de la libertad realizada. Sin embargo, lo más endeble en este filósofo en su propio sistema.

La búsqueda por Herman Cohen y Paul Natorp de una filosofía primera legitimada en el método naturalista expresa una contradicción con el propio método de Kant, quien superó hasta cierto punto la tradición natural del entendimiento. La matemática de la naturaleza del pensamiento humano planteada por Cohen es antikantiana, porque es una vía donde se piensa la relación sujeto- predicado con identidad, al respecto Kant planteó que "los juicios matemáticos son todos ellos sintéticos" $"$. La dialéctica idealista kantiana aparece con los juicios analíticos, "son pues aquellos en los cuales el enlace del predicado con el sujeto es pensado mediante identidad"77, pero la matemática solo amplía el conocimiento, en tanto proposiciones sintéticas, según Kant estas solo "[...] añaden al concepto del sujeto un predicado que no estaba pensado en él y no hubiera podido sacarse por análisis alguno"78,

75. HEGEL, Federico Guillermo: Fundamentos de la filosofía del derecho, Madrid: Libertarias. Prodhufi, 1993, Pág. 1.

76. KANT, Immanuel: Crítica de la razón pura, ob. cit. Pág. 56.

77. Ibíd. Pág. 54.

78. Ibíd. Pág. 55.

Revista de Ciencias Sociales - Número 70 (2017) - Universidad de Valparáíso - ISSN 0716-7725-Valparáiso, Chile 
mientras la "filosofía trascendental [...], tiene como propósito no la ampliación de los conocimientos, sino sólo la rectificación de los mismos, y debe proporcionar la piedra de toque del valor o no valor de todos los conocimientos a priori" ${ }^{\prime \prime 9}$.

3. De la medida en la lógica hegeliana a la medida en la estructura social

\subsection{Lévi-Strauss: medida, estructura social y superación científica del idealismo hegeliano}

Desde una perspectiva antropológica Claude Lévi-Strauss sitúa la "medida" en los análisis estructurales que "[...] han hecho posible el relacionar los valores numéricos con las invariables. Por ejemplo — dice_-, este fue el resultado de las investigaciones sobre la moda femenina de Kroeber" ${ }^{80}$. No hace alusión a Hegel, tal vez es debido a una deducción del concepto "medida" sobre bases filosóficas materialistas, hecho significante en la superación científica del idealismo objetivo hegeliano. Lévi-Strauss parece consciente del proceso de dialectización de su ciencia cuando advierte que "se debe de tener presente que no hay una conexión necesaria entre la medida y la estructura" ${ }^{81}$. De ahí que esta no es, en esencia, una relación cuantitativa ni puede reducirse a la cantidad, menos identificarla con la realidad empírica, más bien está relacionada "con los modelos que se han construido a partir de ésta [...], no puede reclamar un campo específico" ${ }^{2}$; pero es "un método que se tiene que aplicar a cualquier clase de estudios sociales, similar a los análisis estructurales que son normales en otras disciplinas" $"$.

79. Ibíd. Pág. 56.

80. LÉVI-STRAUSS, Claude: "La estructura social”. En: Bohannan, Paul y Glazer, Mark (compiladores): Antropología. Lecturas, Segunda edición, La Habana: Editorial Félix Varela, 2005. Pág. 444.
81. Ídem.
82. Ibíd. Pág. 441.
83. Ibíd. Pág. 442.

Facultad de Derecho y Ciencias Sociales - Universidad de Valparaíso - Chile 
Más adelante señala: "Y, por último, el modelo debe constituirse de manera que pueda hacer de forma inmediata todos los hechos observados, inteligibles" ${ }^{\prime 4}$. El problema del concepto "estructura social" es replanteado en la antropología straussiana, adquiriendo cierta distancia de la manera en que era entendida tradicionalmente. Si para muchos antropólogos, "las descripciones, análisis y las teorías relacionadas con las relaciones sociales" ${ }^{15}$ constituyen su ámbito, Lévi-Strauss entenderá algo diferente: esos conceptos serán ahora significativos, porque su "noción de estructura tiene una estructura" ${ }^{86}$, es decir, le interesa el modelo cognitivo construido, la tarea del pensamiento antropológico aquí está sentada en el análisis de las "direcciones del término 'estructura social' y "como lo han usado los diferentes autores" 87 . El concepto debe expresar una comprensión más rigurosa del proceso de establecimiento de los modelos de una cultura. Y como quiera que sea, con Lévi-Strauss se dinamiza la toma de conciencia epistemológica y metodológica del antropólogo; ya que se trata de un pensamiento no limitado a la observación de la realidad, sino a cierta forma objetiva de crítica a determinados esquemas precedentes.

El tomar conciencia de la diferenciación conceptual aludida lleva a Lévi-Strauss a interrelacionar la construcción de modelos de los fenómenos culturales, los modelos construidos por la propia cultura, las normas culturales y la escala del modelo y la de los fenómenos, sin descuidar su concepto de estructura social. Así habla de "modelo mecánico" y "modelo estadístico". Todo anclado de una u otra forma en los problemas de método. Estas distinciones y la diferenciación de los modelos o tipos de estructuras sociales se vinculan a las culturas reales. "Así, la pregunta es saber qué clase de modelo merece el nombre de 'estructura'. Esta no es una pregunta antropológica, sino una que pertenece a la metodología de la ciencia en general" ${ }^{88}$. Pregunta que

\footnotetext{
84. Ídem.

85. Ibíd. Pág. 440.

86. Ibíd. Pág. 441.

87. Ídem.

88. Ibíd. Pág. 442.
}

Revista de Ciencias Sociales - Número 70 (2017) - Universidad de Valparáíso - ISSN 0716-7725-Valparaíso, Chile 
preside la fundamentación teórica del método científico y plantea al conocimiento problemas cuya solución exige separar partes a la manera de las reglas matemáticas y construir categorías, leyes y principios estrechamente relacionados con la concepción dialéctica del mundo.

Por eso, el método será conforme a la realidad cuando el modelo en cuestión "pueda hacer de forma inmediata todos los hechos observados, inteligibles" ${ }^{\$ 9}$. En los marcos concretos de su objeto, pudiera objetarse posiciones de Lévi-Strauss, pero llegados a este punto poco durará aquel que comprenda la dimensión epistémica de calar el recorrido histórico de la ciencia antropológica y los intentos de estudiar datos cualitativos con lo que llama modelos mecánicos y datos cuantitativos con modelos de naturaleza estadística. El primer aspecto a destacar sería por tanto el de comprender estos modelos que, según Lévi-Strauss, "nos ayudará a esclarecer la naturaleza dual (y en el primer momento casi contradictoria) de los estudios estructurales" $"$.

Esta vía de los estudios estructurales sitúa a Lévi-Strauss en el campo que deja "a un lado las fuerzas tradicionales entre las diferentes disciplinas" ${ }^{91}$ e incluye la promoción de "un enfoque verdaderamente interdisciplinario" ${ }^{2}$ y llega a reconocer "una expresión matemática de los fenómenos sociales" 93 que ciencias como la demografía, sociología, antropología elaboraban en forma de "propiedades numéricas de los grupos humanos" ${ }^{\text {", }}$ esto es cierta "especie de demografía cualitativa"; reconociendo a su vez que esta desborda los límites de la cantidad, dado que no es suficiente en sí misma para redactar las conclusiones "[...], es decir, no trabajan ya con las variaciones continuas de los grupos humanos que han sido seleccionados por razones empíricas, sino con discontinuidades significativas evidenciadas por las conductas de los
89. Ídem.
90. Ibíd. Pág. 446.
91. Ídem.
92. Ídem.
93. Ibíd. Pág. 451.
94. Ídem.

Facultad de Derecho y Ciencias Sociales - Universidad de Valparaíso - Chile 
grupos considerados como un todo y que han escogidos por estas discontinuidades" ${ }^{95}$.

\title{
3.2. Continuidad, discontinuidad y cultura
}

La discontinuidad, "discreción” para Hegel, aparece aquí como momento separable metódicamente, pero inseparable del proceso total de construcción de la estructura social. Así, a diferencia de la continuidad, el cambio discontinuo es propio "[...] de las propiedades numéricas que no expresan el tamaño del grupo globalmente, sino el tamaño e interacción de los subgrupos del grupo que se puede definir con discontinuidades significativas $[\ldots]{ }^{" 96}$. Lévi-Strauss casi siempre habla en términos de posibilidad de este método, nunca niega la relación de culturas diferentes. El problema contiene una solución dialéctica de la categoría "medida". A cada cultura cualitativamente individual, le son inherentes rasgos cuantitativos, aunque nunca la estructura social (mental) del grupo queda reducida, dada su naturaleza, a la cantidad. La medida expresa la unidad (contradictoria) entre el par cualidadcontinuidad y cantidad-discontinuidad. Continuidad y discontinuidad son momentos lógico-históricos esenciales, y ahora sí, necesarios. Es por ello que Lévi-Strauss al menos se dispone aprehender este momento lógico para guiar su pensamiento antropológico:

Lo que se llama una 'cultura' es un fragmento de humanidad, que, desde el punto de vista de la investigación de que se dispone y de la escala con que se lleva a cabo, presenta, en relación con el resto de la humanidad, discontinuidades significativas. Si nuestro propósito es el de averiguar las discontinuidades significativas entre, por ejemplo, América del Norte y Europa, entonces estamos trabajando con dos culturas diferentes; pero si nos ocupáramos de las discontinuidades significativas entre Nueva York y Chicago, podríamos hablar de esos dos grupos como 'unidades' culturales diferentes ${ }^{97}$.

Esa afirmación sería imposible sin la comprensión matemática de las sucesiones continuas o infinitas. Las estructuras sociales no son

\author{
95. Ibíd. Págs. 451-452. \\ 96. Ibíd. Pág. 452. \\ 97. Ibíd. Págs. 453-454. \\ Revista de Ciencias Sociales - Número 70 (2017) - Universidad de Valparáíso - ISSN 0716-7725-Valparaíso, Chile
}


lineales, sino dialécticas. La discontinuidad es un momento de la cantidad, como la continuidad. Lévi-Strauss encuentra aquí alguna solución del problema de las relaciones entre humanidad (lo universal) y una cultura (lo singular), señalando fundamentalmente determinadas cuestiones de la lógica del desarrollo de las matemáticas y de la teoría de la comunicación:

Los estudios estructurales son, en las ciencias sociales, el resultado indirecto de los desarrollos modernos en matemáticas, que le han dado una importancia cada vez mayor al punto de vista cualitativo, enfrentado al punto de vista cuantitativo de las matemáticas tradicionales. Así, se ha hecho posible, en campos tales como la lógica matemática, la teoría en conjunto, la teoría en grupo y la topología, desarrollar un enfoque riguroso con los problemas que no admiten una solución métrica [...] Los logros más notables en esta conexión [...] se pueden encontrar en J. Von Neumann y O. Morgenstern, Theory of Games And Economic Behavior (1944); N. Winer, Cybernetics (1948); y C. Shannon y W. Weaver, The Mathematical Theory of Communication $(1950)^{98}$.

Es verdad que Shannon desde 1949 desplegó una labor teórica que trascendió los enfoques reduccionistas de la mecánica clásica y los modelos de ciencia positiva. La entropía, el desorden y la desintegración las explicó en forma matemática y la llevó de la termodinámica a los sistemas de información. La teoría en torno a los sistemas le permitió explicar y construir los comportamientos de sistemas macroscópicos al extender la probabilidad no sólo a la desinformación sino a la información, y con ello fundamentó las bases de la comprensión de la "entropía" como desinformación que se opone a la "neguentropía" como información. Manejó los conceptos de sistemas abiertos y cerrados, los cuales tienden a aprender la dinámica compleja de la realidad. Así a los "sistemas cerrados" que pierden información se oponen los "sistemas abiertos" aptos en la conservación o adquisición de más "información”. Del determinismo mecanicista que explicaba el universo, se pasó a lo posible de crear ${ }^{99}$.

\footnotetext{
98. Ibíd. Págs. 444-445.

99. Véase al respecto CASANOVA GONZÁLEZ, Pablo: Las Nuevas Ciencias y las Humanidades. De la Academia a la Política, Madrid: Editorial Complutense, 2004. Pág. 45.
}

Facultad de Derecho y Ciencias Sociales - Universidad de Valparaíso - Chile 
En el enfoque de Lévi-Strauss subyace una crítica al cientificismo objetivista que pretende dominar siempre a cada una de las disciplinas. La construcción del objeto en su pensamiento no se reduce a una simple tarea de selección, descripción e interpretación de textos y datos ya sean ideas, diálogos, signos, etc., y luego traspolarlos artificiosamente a modelos o esquemas reducidos al emisor y el receptor, en el caso de la teoría de la comunicación. La epistemología no quita importancia a la multidisciplinariedad que suscita las reflexiones sociológicas, históricas, lingüísticas, etc. Su método se justifica ante la complejidad de la construcción teórica. Este es el saldo obligado, más que aceptar en todas sus dimensiones este método.

Lévi-Strauss critica al antropólogo Radcliffe-Brown, porque en este "[...] la noción de estructura significa [...] una forma de unir la antropología social con las ciencias biológicas [...] Entonces, en vez de 'elevar' los estudios de parentesco para ponerlos al mismo nivel de la teoría de comunicación [...], él los ha rebajado hasta el mismo plano que los fenómenos relacionados con la morfología y fisiología descriptiva [...]" ${ }^{100}$. No obstante, es necesario aclarar que ambos antropólogos como parte de la orientación sociocultural niegan que los datos arqueológicos e históricos sean referentes positivistas auxiliares para describir las etnias de acuerdo con un presupuesto antropométrico al margen de su origen y formación. El positivismo de Spencer y las teorías de Darwin, en cambio, fueron pilares fundamentales de esa forma de demostrar las diferencias, en donde el indígena era considerado un atavismo ante el paradigma modernizador ${ }^{101}$, el cual evadió la pertenencia de estos grupos al proceso de formación de las nacionalidades.

En Lévi-Strauss hay una reacción implícita antievolucionista contra el "transformismo" de Haeckel, Buffon, la Naturphilosophie, Lamarck, Lyell, la teoría de la evolución biológica; Wallace, Sobre las tendencias de las variedades a separarse indefinidamente del tipo original;

\footnotetext{
100. LÉVI-STRAUSS, Claude: “La estructura social”, ob. cit. Pág. 460.

101. Véase al respecto HALE, Charles: "Political and social Ideas in Latin America, 1870-1930. En: The Cambridge History of Latin America, Cambrige: Editorial, L. Bethell, Cambridge University Press vol. 4, 1986. Págs. 396-406.
}

Revista de Ciencias Sociales - Número 70 (2017) - Universidad de Valparaíso - ISSN 0716-7725-Valparaíso, Chile 
Darwin, El Origen de las Especies, etc., que defendían el descriptivismo natural del método etnográfico y el determinismo biológico taxonómico de las razas inferiores, los cuales sustentaron básicamente las tesis en torno a la degeneración por cruzamientos étnicos y la obtención de razas mejoradas, apegados a la inmediatez de los datos hicieron suyo una historiografía deficiente en la comprensión histórica del hombre político moderno de la civilización occidental; porque no tendió a reconstruir los procesos de transformación social de prácticas culturales generadas por la influencia recíproca entre etnias diferentes conforme a categorías históricas definidas, gracias a las cuales es posible identificar teóricamente una imagen histórica específica de semejante hombre moderno.

Lévi-Strauss dice también sobre Radcliffe-Brown que: "Su filosofía es de continuidad, no de discontinuidad; esto nos indica su hostilidad hacia la noción de cultura [...], y que evita la enseñanza de la lingüística estructural y las matemáticas modernas" ${ }^{102}$. El problema de las relaciones entre humanidad (lo universal) y una cultura (lo singular), señalado por Lévi-Strauss desde cuestiones de la lógica del desarrollo de las matemáticas y de la teoría de la comunicación antes aludidas implica además, cierta reacción implícita contra el sistema de Augusto Comte, que patentaba dependencias lógicas normativas reservadas para la eternidad. La comprensión matemática de las sucesiones continuas o infinitas constituye un viraje específico antievolucionista. La dialéctica referida entre el par cualidad-continuidad y cantidad-discontinuidad como momentos lógico-históricos esenciales y necesarios es una oposición teórica frente a la lucha, el progreso, la perfección y la competencia erigidos en un reduccionismo interpretativobiológico de la sociedad, el cual lanzó la tesis de que las especies vivientes sugerían una historia del hombre en los mismos términos, al margen de sus procesos histórico-sociales de producción.

Cuando Lévi-Strauss precisa que: "El campo del mito, ritual y la religión parece, sin duda, uno de los más fructíferos para el estudio de la estructura social" ${ }^{103}$ es debido a un modelo diseñado opuesto al

102. LÉVI-STRAUSS, Claude: "La estructura social”, ob. cit. Pág. 461.

103. Ibíd. Pág. 467.

Facultad de Derecho y Ciencias Sociales - Universidad de Valparaíso - Chile 
programa "científico" socialdarwinista de que el hombre entraba en el mundo de la naturaleza y el conocimiento para determinar exclusivamente hechos positivos sujetos a la observación. Solo así, según los darwinistas sociales, podría expulsarse el absurdo de lo sagrado en la interpretación de la realidad natural y en la dirección y organización de la vida humana.

\subsection{Orden, estructura social, lo cualitativo y la continuidad}

En el epígrafe "Orden de los órdenes”, Lévi-Strauss afirma que la "[...] antropología considera toda la estructura social como una red de diferentes tipos de órdenes. El sistema de parentesco le proporciona una manera de ordenar a los individuos de acuerdo con ciertas reglas; la organización social es otra manera de ordenar a los individuos y grupos; las estratificaciones sociales, tanto si son económicas como políticas, nos dan otro tipo [...]"104. Puede verificarse en esta aseveración una reflexión epistémica sobre la política en correspondencia con los cambios operados en la sociedad y la cultura en sentido general. La antropología de Lévi-Strauss intenta integrar la estructura social (mental) a la totalidad de las relaciones humanas incluso del cosmos, desde el momento en que su reflexión desplazó el orden evolucionista por el orden cultural.

Ese problema expresa la razón misma del pensar dialéctico. La historiografía filosófica y científica no siempre advierte que la universalización de la dialéctica también fue fortalecida, precisamente, en el campo de la antropología ahora dentro del orden de la totalidad. Dichas posibilidades epistemológicas y metodológicas de un tratamiento de los modelos cognitivos puede oponerse resueltamente al positivismo que atacó la formulación de la justicia. Lo justo para Augusto Comte sería solo garantizado por el orden social, político y jurídico concreto, una idea popular recogida en su obra Sistema de política positiva (18511854):

Cada uno tiene deberes, y los tiene frente a todos; pero que ninguno tiene un derecho propiamente dicho [...] la palabra derecho

104. Ídem.

Revista de Ciencias Sociales - Número 70 (2017) - Universidad de Valparaíso - ISSN 0716-7725-Valparáíso, Chile 
debe ser eliminada del lenguaje verdaderamente político por ser creación tecnológico-metafísico" ${ }^{105}$. Por otra parte, Comte advertía en su obra El catecismo positivista, que "el positivismo no reconoce ningún otro derecho que el de hacer siempre el propio deber. Todo derecho humano es tan absurdo como inmoral ${ }^{106}$.

El concepto de deber sostenido desde el positivismo coincidió también con el positivismo jurídico legalista formulado por John Austin, quien consideraba el derecho positivo como simple mandato del soberano, entendido este como el detentador del poder político en la sociedad ${ }^{107}$. Hans Kelsen, llegó a propugnar que la justicia era una propiedad solo presente en el acto normativo ${ }^{108}$. Ahora, Lévi-Strauss apunta que "podría decirse que, en nuestra sociedad, la ideología política puede que pertenezca a la misma categoría" de los "órdenes imaginados [...] del mito y la religión”"109, por tanto, es una reflexión que busca la identidad y diferenciación de la estructura social con la totalidad (lo cualitativo y la continuidad o lo universal). Su fundamentación parte de la posición y función del ser de la estructura social en la totalidad. Así, el pensamiento no se limita a la descripción positivista de los modelos cognitivos, sino que también trató de lo que es el orden. De modo que el principio metodológico indica que una indagación sobre el ser de la estructura social o modelo cognitivo tiene un sentido de relación, por ejemplo, con la moral.

Cuando Lévi-Strauss habla de "Dinámica social” y "Estática social" no lo hace exactamente en los términos de Comte, sino de la

105. Citado por FASSÓ, Guido: Historia de la Filosofía del Derecho I. Antigüedad y Edad Media, Madrid: Ediciones Pirámides, S.A, 1982. Pág. 31.

106. Ídem.

107. Véase al respecto AUSTIN, John: Sobre la utilidad del estudio de la Jurisprudencia, Madrid: Centro de Estudios Constitucionales, 1981. Trad. al español de F. González Vicén.

108. Véase al respecto KELSEN, Hans: Teoría General del Derecho y del Estado, México: Universidad Nacional Autónoma de México, 1995.

109. LÉVI-STRAUSS, Claude: "La estructura social”, ob. cit. Pág. 467.

Facultad de Derecho y Ciencias Sociales - Universidad de Valparaíso - Chile 
lógica referida que precede su concepto de estructura social: "1) ¿Puede la estructura de parentesco por sí misma, dar como resultado estructuras de un nuevo, es decir, orientadas dinámicamente? 2) ¿Cómo tienen influencia las estructuras de comunicación y las de subordinación una con otra?" 110 . El propio Lévi-Strauss añade al respecto que "ha intentado establecer que la relación que hay entre la terminología y la conducta tiene una naturaleza dialéctica" 111 . Previamente había dicho que "como consecuencia, sería posible trasladar los modelos estadísticos a mecánicos y viceversa, llenando así el vacío existente en los estudios de población, por una parte, y los antropológicos, por otra, estableciendo una base para predecir una acción”"112. La relación dinámica se expresa en una conducta dinámica de "derechos, deberes, obligaciones y, por otra parte, en los privilegios, anulación, etc." ${ }^{113}$, problemáticas sobre estáticas de parentesco derivadas de la teoría de la comunicación y ventiladas dentro del enfoque dialéctico.

\section{Conclusiones}

La filosofía griega enseña que no tiene el mismo alcance reseñar los nombres de las ciencias que elaborar un concepto de ciencia, para ello es imprescindible el empleo de la razón. El filósofo construye una explicación totalizadora con el empleo de cierto método de indagación. Este proceso de construcción del conocimiento lleva a planteamientos de problemas, cuya solución abandona las apariencias y descubre la esencia, algo más allá de la realidad física sensible. Es lo que pretendió Platón cuando aborda, dentro de la reflexión sobre números, el problema de la unidad; porque permitiría rebasar la apariencia tangible. El método dialéctico hegeliano y el ideal científico que le acompaña es portador, en sentido general, del concepto platónico de filósofo. El filósofo debe

\footnotetext{
110. Ídem. Pág. 465.

111. Ídem.

112. Ibíd. Pág. 456

113. Ibíd. Pág. 465.
}

Revista de Ciencias Sociales - Número 70 (2017) - Universidad de Valparáíso - ISSN 0716-7725-Valparaíso, Chile 
abordar la correlación de las ciencias y la dialéctica y establece el método considerado como medio único capaz del reflejo del ser y la determinación universal. Ello implica una problematización rigurosa de la realidad.

La verdad del conocimiento dialéctico, de tal forma, comprueba que la conciencia religiosa no capta la transición enraizada en el movimiento. Es precisamente el reconocimiento de la unidad entre identidad y diferencia la característica de la lógica interna del desarrollo. La dialectización de la matemática que inicia, o toma auge con la magnitud variable de Descartes y complementado por el desarrollo del cálculo diferencial e integral por parte de Newton y Leibniz, le sirvió a Hegel para reafirmar su ideal del conocimiento científico.

Desde una perspectiva antropológica Claude Lévi-Strauss, por su parte, sitúa la "medida" en los análisis estructurales como un principio de la comprensión más rigurosa del proceso de establecimiento de los modelos de una cultura. Este antropólogo considera que a cada cultura cualitativamente individual, le son inherentes rasgos cuantitativos, aunque nunca la estructura social (mental) del grupo queda reducida a la cantidad. La medida expresa la unidad (contradictoria) entre el par cualidad — continuidad y cantidad - discontinuidad. Continuidad y discontinuidad son momentos lógico-históricos esenciales, por tanto, necesarios.

Es por ello que Lévi-Strauss se dispone aprehender ese momento lógico para guiar su pensamiento antropológico y sin prejuicio alguno señala formas de conexión causal de estados estructurales concretos de las culturas, donde destaca regularidades estadísticas que están actuando en los modelos cognitivos cualitativamente nuevos que parten de dinámicas previas. He ahí su planteamiento de la posibilidad de trasladar los modelos estadísticos a modelos mecánicos y viceversa en los estudios demográficos, antropológicos e incluso sociológicos, siempre en la búsqueda de la mejor forma de calcular la información del sistema de las sociedades complejas y simples.

\section{Bibliografía}

ARISTÓTELES: Metafísica. Política, Editorial Estudios, La Habana, 1968.

Facultad de Derecho y Ciencias Sociales - Universidad de Valparaíso - Chile 
ARISTÓTELES: Ética Nicomaquea. Política, Editorial Porrúa, S.A., México, 1979.

AUSTIN, John: Sobre la utilidad del estudio de la Jurisprudencia: Centro de Estudios Constitucionales, Madrid, 1981 (trad. al español de

F. González Vicén).

CASANOVA GONZÁLEZ, Pablo: Las Nuevas Ciencias y las Humanidades. De la Academia a la Política, Editorial Complutense,

Madrid, 2004.

FASSÓ, Guido: Historia de la Filosofía del Derecho I. Antigüedad y Edad Media, Ediciones Pirámides, S.A, Madrid, 1982.

HALE, Charles: "Political and social Ideas in Latin America, 18701930. En: The Cambridge History of Latin America, Editorial, L. Bethell. vol. 4.Cambridge University Press, 1986.

HEGEL, Federico Guillermo: Lecciones sobre historia de la filosofía, Tomo I, Fondo de Cultura Económica, México, 1955.

HEGEL, Federico Guillermo: Ciencia de la lógica, Editorial Hachette, Buenos Aires, 1956. (Trad. de R. Mondolfo).

HEGEL, Federico Guillermo: Fundamentos de la filosofía del derecho, Libertarias. Prodhufi, Madrid, 1993.

HEGEL, Federico Guillermo: Fenomenología del espíritu. En: Dominic Oliva, Eduardo (comp): Antología. Historia de la Filosofía.

Filosofía Clásica Alemana, Tomo V, Editorial Félix Varela, La Habana, 2013.

KANT, Emmanuel: "Crítica de la razón pura”. En: Eduardo Dominic Oliva: Antología. Historia de la Filosofía. Tomo V. Filosofía Clásica Alemana, Editorial Félix Varela, La Habana, 2013.

KANT, Emmanuel: Introducción a la Teoría del Derecho, Instituto de Estudios Políticos, Madrid, 1964.

KANT, Emmanuel: Metafísica de las Costumbres, Madrid, Tecnos, 1989. (Trad. y notas de Adela Cortina Orts y Jesús Conill Sancho).

KELSEN, Hans: Teoría General del Derecho y del Estado, Universidad Nacional Autónoma de México, México, 1995.

LÉVI-STRAUSS, Claude: "La estructura social”. En: Bohannan, Paul y Glazer, Mark (compiladores): Antropología. Lecturas, Segunda edición, Editorial Félix Varela, La Habana, 2005. 
PLATÓN: Alcibíades o de la naturaleza del hombre. Obras Completas, Ediciones Florida 251. Anaconda, Buenos Aires, 1946. (Trad. de P. De Azcárate).

PLATÓN: La República, Editorial de Ciencias Sociales, La Habana, 2008.

SPINOZA, Baruch: Ética, Editorial de Ciencias Sociales, La Habana, 2006.

Facultad de Derecho y Ciencias Sociales - Universidad de Valparaíso - Chile 